\title{
Article \\ Potencial Use of Near Infrared Spectroscopy (NIRS) to Categorise Chorizo Sausages from Iberian Pigs According to Several Quality Standards
}

\author{
Alberto Ortiz (D), Lucía León *(D), Rebeca Contador (D) and David Tejerina (D) \\ Meat Quality Area, Center of Scientific and Technological Research of Extremadura (CICYTEX-La Orden), \\ Junta de Extremadura, Ctra A-V, Km272, 06187 Guadajira, Spain; alberto.ortiz@juntaex.es (A.O.); \\ rebecontro@gmail.com (R.C.); david.tejerina@juntaex.es (D.T.) \\ * Correspondence: lucia.leon@juntaex.es
}

check for updates

Citation: Ortiz, A.; León, L.; Contador, R.; Tejerina, D. Potencial Use of Near Infrared Spectroscopy (NIRS) to Categorise Chorizo Sausages from Iberian Pigs According to Several Quality Standards. Appl. Sci. 2021, 11, 11379. https://doi.org/ 10.3390/app112311379

Academic Editors: Mike Boland and Alessandra Biancolillo

Received: 8 October 2021

Accepted: 29 November 2021

Published: 1 December 2021

Publisher's Note: MDPI stays neutral with regard to jurisdictional claims in published maps and institutional affiliations.

Copyright: (c) 2021 by the authors. Licensee MDPI, Basel, Switzerland. This article is an open access article distributed under the terms and conditions of the Creative Commons Attribution (CC BY) license (https:/ / creativecommons.org/licenses/by/ $4.0 /)$.

\begin{abstract}
The ability of Near Infrared Spectroscopy (NIRS) to classify pre-sliced Iberian chorizo modified atmosphere packaged (MAP) according to the animal material used in their production (Black, Red, White) in their production in accordance with the official trade categories (which includes the handling system and the different inter-racial crossbreeds) without opening the package was assayed. Furthermore, various spectra pre-treatments and supervised classification chemometric tools; Partial least square-discriminant analysis (PLS-DA), soft independent modelling of class analogies (SIMCA) and linear discriminant analysis (LDA), were assessed. The highest sensitivity values in both calibration and external validation were achieved with SIMCA followed by PLS-DA approaches, while LDA had more provided values among sensitivity and specificity and between the different commercial categories in both sample sets, thus yielding the highest discriminant ability. These results could be a resource to support the traceability and authentication control of individual pre-sliced MAP Iberian chorizo according to the commercial category of the raw material in a non-destructive way.
\end{abstract}

Keywords: PLS-DA; SIMCA; LDA; unopened package; modified atmosphere packaging

\section{Introduction}

The Iberian Spanish market provides a wide variety of traditional meat and meat products, being dry-cured ones of great relevance in the Spanish diet and being also widespread among Mediterranean countries [1], mainly due to its nutritional sensory quality attributes. The quality of Iberian dry-cured products is dependent on the intrinsic characteristics of raw material (meat and fat used for its production) from which they are made, which in turn is dependent on animal production conditions. Thus, the genetic background (purebred Iberian pigs vs. Iberian crossed with Duroc), the rearing conditions (indoors vs. outdoors systems) or the type of feed received, especially in the last stage of fattening (based on natural feed vs. commercial fodder), led to a large degree of variability in the physico-chemical [2-4] and sensory attributes [5] of meat and meat products. The current Spanish Iberian Quality Standard (IQS) [6], includes the different quality categories obtained from the combinations of the above-mentioned factors. Thus, the standard officially sets out four quality levels, which are described on different commercial labels; "Black" (100\% Iberian pigs that finish their fattening stage in Montanera-reared in the outdoors with feed-based exclusively on the ad libitum consumption of acorns mainly from Quercus ilex and grass-), "Red" (pigs with a minimum Iberian purity of 50\%, which finish their fattening phase in Montanera), "Green" (pigs with a minimum Iberian purity of 50\%, reared in outdoor conditions and fed with commercial fodder-mainly based on cereals and leguminous plants-without prejudice that they may also consume acorns and grass) and "White" (animals of at least 50\% purebred Iberian, reared indoors and fed exclusively 
on commercial fodder). Nevertheless, these quality degrees are not applicable to all meat products, and exclude some such as Iberian dry-cured sausages, while others, such as fresh meat, dry cured hams, shoulders and loin, are included.

Recently, García-Gudiño et al. [7] highlighted the relevance of labelling in the perception of the Iberian products by consumers. Thus, the inclusion of Iberian dry-cured sausages such as chorizo into the various quality degrees or commercial categories abovementioned would provide information regarding its quality dimension, and the possibility of being commercially recognized as a classified and authenticated product by the current IQS [6].

The physico-chemical and organoleptic differences among Iberian chorizo manufactured from raw meat from three commercial categories (Black, Red and White) included in the current IQS [6] have been recently addressed by García-Torres et al. [8]. So, current efforts should be focused on seeking tools to provide a quality control of Iberian chorizo according to the commercial category of the raw material, thus protecting its authenticity, and supporting a labelling system that provides added value to this product as well as reliability in terms of traceability and quality control to the consumer.

On the other hand, there is a trend towards the use of vacuum or modified atmosphere packaging (MAP) of sliced products as compared to the entire piece in the selling formats of meat products. In particular, the similarity to a hand-sliced product provided by MAP packaging compared to the traditional appearance of vacuum packaging, favours the tendency to choose MAP over vacuum packaging [9]. However, given their dispersion from the original whole piece, pre-sliced packaged products could be more exposed to fraudulent practices. So, quality authentication is essential in pre-sliced package selling formats.

In this regard, near infrared reflectance spectroscopy (NIRS) is a fast, sensitive, and non-destructive technology that has been previously used for Iberian pig carcasses, subcutaneous fat and fresh meat classification according to the current official commercial categories by Horcada et al. [10]. In addition, qualitative studies have been carried out with NIRS to study the possibility to classify pre-sliced MAP Iberian dry-cured loin according to the above-mentioned official commercial categories [11], showing both studies acceptable classification results into various official commercial categories [6]. However, so far, we are not aware of any other studies where the viability of this tool has been studied in a qualitative way to classify Iberian dry-cured sausages.

Thus, the objective of the present work was to assess the ability of the NIRS technology for pre-sliced MAP Iberian chorizo classification within various official commercial categories defined by the current IQS of the raw meat used for their manufacturing (Black, Red and White).

\section{Materials and Methods}

\subsection{Meat Sampling and Experimental Design}

A total of 103 samples of 100 g-packages under MAP of Iberian chorizo manufactured from raw material belonging to three official commercial categories [6] (Black $(n=32)$, Red $(n=35)$ and White $(n=36))$ were purchased from an Iberian manufacturing industry and used in the current study.

The management of the animals was in accordance with those defined for each commercial category by the current IQS [6], and are summarized in Figure 1. There is a fourth category contemplated by the IQS Green commercial category- which was not included in the experimental design of the current study owing to the large variability resulting from involving animals under different production system conditions (various percentages of Iberian breed, open-air reared and fed on fodder but without detriment that they may also be fed on acorns and grass in the Montanera system) [6]. 

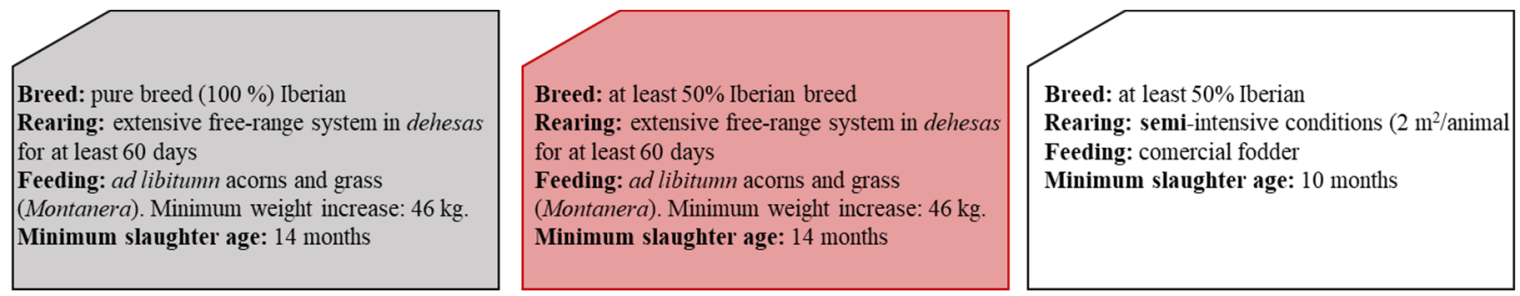

Figure 1. Production system conditions required in Black, Red and White commercial category according to the current Spanish Iberian Quality Standard.

Iberian chorizo was manufactured as follows. To the initial sausage batter composed of $52 \%$ of lean and $48 \%$ of back fat from animals under production systems of Black, Red and White commercial categories, respectively, $2 \mathrm{~g} / 100 \mathrm{~g}$ of NaCl, $2 \mathrm{~g} / 100 \mathrm{~g}$ of paprika and $2 \mathrm{~g} / 100 \mathrm{~g}$ of additives (dextrose, lactose) and authorized preservatives and stabilizers (E-250, E-252, E-331) specially prepared for this type of Iberian dry-cured sausages products were added. Three sample production batches were used, one for each commercial category, to which were added the same amount and composition of preservers and stabilizers. Thereafter, Iberian chorizo mass batches were kept at refrigeration temperature $\left(4 \pm 2{ }^{\circ} \mathrm{C}\right)$ for $24 \mathrm{~h}$, allowing the homogeneous seasoning mixture distribution. Subsequently, Iberian chorizo were stuffed into 6-7 cm diameter natural casing in order to start the fermentation and ripening process, which was carried out in accordance with the common techniques of the Iberian processing industry. The fermentation was carried out at $22 \pm 2{ }^{\circ} \mathrm{C}$ and $85 \%$ of relative humidity (RH) for $48 \mathrm{~h}$ and $10-15{ }^{\circ} \mathrm{C}$ and $85 \% \mathrm{RH}$ for 10 days. Then, the $\mathrm{RH}$ was slowly decreasing (drying) to $70 \% \mathrm{RH}$ until the end of the ripening process. The total length of the process differed accounting on characteristics of meat and back fat of each commercial category, being the total process length: 120, 110 and 100 days for Iberian chorizo pieces manufactured from raw material with Black, Red and White commercial categories, respectively, and the average weights per piece were $1.3 \pm 0.3,1.4 \pm 0.1$ and $1.4 \pm 0.3 \mathrm{~kg}$, respectively. After this, using an industrial slicer, the chorizos were sliced into $2 \mathrm{~mm}$ thickness slices in a slicing plant in a clean room and packaged in $100 \mathrm{~g}$ packs under MAP (Ulma ${ }^{\circledR}$ SMART 300). Atmosphere composition consisted in a mixture of gases $\left(70 \% \mathrm{~N}_{2}\right.$ and $\left.30 \% \mathrm{CO}_{2}\right)$. The material of the packaging used was polystyrene $(150 \mathrm{~mm}$ thick) with an oxygen permeability of $3.2 \mathrm{~cm}^{3} \mathrm{O}_{2} / \mathrm{m}^{2} / 24 \mathrm{~h} / \mathrm{atm}$ at $4{ }^{\circ} \mathrm{C}$ and sealed with $70 \mathrm{~mm}$ thick polyethylene film (VIDUCA, Alicante, Spain) with an oxygen permeability of $1 \mathrm{~cm}^{3} / \mathrm{m}^{2} / 24 \mathrm{~h}\left(4{ }^{\circ} \mathrm{C} ; 50 \% \mathrm{RH}\right), 5.5 \mathrm{~cm}^{3} / \mathrm{m}^{2} / 24 \mathrm{~h}\left(4{ }^{\circ} \mathrm{C} ; 50 \% \mathrm{RH}\right)$ to $\mathrm{CO}_{2}$ and $2.2 \mathrm{~g} / \mathrm{m}^{2} / 24 \mathrm{~h}$ $\left(4{ }^{\circ} \mathrm{C} ; 90 \% \mathrm{RH}\right)$ to $\mathrm{H}_{2} \mathrm{O}$.

\subsection{Near Infrared Spectroscopy Spectral Measurements and Multivariate Data Analysis}

Spectra data were obtained in reflectance mode and acquired by using the instrument LabSpec 2500 (ASD Inc., Madrid, Spain) fitted with an ASD fibre-optic Contact Probe ${ }^{\circledR}$ (21-mm window diameter). Before obtaining the spectra, NIR spectrometer was calibrated using a spectralon tile as the white reference, but covered with the same material with which the pre-sliced MAP Iberian chorizo was packaged, since theobjective of the present study was the spectra acquisition without opening the packages to obtain the predictive models. With the support of the ASD contact probe ${ }^{\circledR}$, a spectrum per packet was obtained with direct sensor-sample contact. In order to reduce errors and increase the sampling area, a zigzag scanning was made over the sample (the entire package, $16 \times 24 \mathrm{~cm}^{2}$ ) (Figure S1). The spectra are the result of the average of 40 scans measured over a range of 1000 to $2300 \mathrm{~nm}$ with a wave number resolution of $2 \mathrm{~nm}$. Instrument monitoring and preliminary spectral manipulation were conducted with the Indico TM Pro software package (Analytical Spectral Device-ASD Inc., Boulder, CO, USA). Thereafter, the collected data were exported to Unscrambler $\mathrm{X}$ vs. 10.5 (CAMO ${ }^{\circledR}$, Trondheim, Norway) for spectra processing and spectra treatments, as well as the development of classification models and their respective external validation. 
All spectra obtained were divided into a calibration set (70\% of the samples) and a external validation set ( $30 \%$ of the samples) (Table 1$)$. Thus, in order to homogeneously represent samples of each class (Black, Red and White) and maximize the variability in both sets, a manual and random selection was performed.

Table 1. Assignment of the number of samples in the calibration and external validation sets in accordance with the commercial labels associated with the raw material used for the production of Iberian chorizo.

\begin{tabular}{ccccc}
\hline & \multicolumn{3}{c}{ Commercial Category } & \multirow{2}{*}{ Total } \\
\cline { 2 - 4 } & Black & Red & White & \\
\hline Calibration & 21 & 25 & 26 & 72 \\
Validation & 11 & 10 & 10 & 31 \\
\hline Total & 32 & 35 & 36 & 103 \\
\hline
\end{tabular}

In order to optimize the accuracy of calibration models by minimizing additive and multiplicative scatter effects and baseline shifts, several spectral math pre-treatments were evaluated: Standard Normal Variate (SNV), Detrend correction (DE) [12] and two different Savitzky-Golay derivatives; the first order derivative with: 4 smoothing left and rightside points (symmetric Kernel), and first polynomial order $(1,4,4,1)$ and the second order derivative: with 5 smoothing left and right-side points, and second polynomial order $(2,5,5,2)[13]$. All pre-treatments and their combinations were evaluated in two spectra regions; $1000-2300 \mathrm{~nm}$ and $1000-1800 \mathrm{~nm}$.

\subsection{Development of Classification Models}

Different qualitative approaches were evaluated with the aim of achieving a classification of pre-sliced MAP Iberian chorizo into official commercial categories of raw material; Partial least squares-discriminant analysis (PLS-DA) and linear discriminant analysis (LDA) as discriminant classification techniques, and soft independent modelling of class analogies (SIMCA) as class-modelling technique (Unscrambler $X$ vs. 10.5 software $\left(C^{2} A O^{\circledR}\right.$, Trondheim, Norway)). Both of them seek to mathematically assign a sample to a given class, however, SIMCA attempts to mathematically confirm whether or not a sample fits into a defined class.

Models were developed based on the calibration set, built on both 1000-2300 nm and 1000-1800 nm spectra range and performed after the different pre-processes and combination of them. The outliers that were found were eliminated. The spectra plot by principal component analysis (PCA) allowed us to detect anomalous samples that gave strange results. It is the most widely used tool for this work. The rules for removing outliers were (1) samples with residuals higher than 2; (2) samples with leverage $(\mathrm{H})$ higher than 3 times the average leverage [14]:

$$
\mathrm{H}=1 /(\mathrm{n}+(\text { number of principal components) } / \mathrm{n})
$$

being " $\mathrm{n}$ " the number of samples.

\subsubsection{Partial Least Squares-Discriminant Analysis}

The PLS-DA model attempts to relate the spectral variances $(X)$ to the Black, Red and White classes to increase the covariance between the two types of variances. In this type of approach, the $\mathrm{Y}$ variables used are categorical "dummy" variables [15], as they are not continuous, as they are in quantitative analysis. In this way, samples that were part of the target class were numbered 1, while otherwise a 0 was assigned [16]. Based on these premises, it is feasible to use this regression method to perform the classification by calculating a calibration model that relates the predictor and the response matrix. Crossvalidation with the leave-one-out method was used to calculate the number of latent 
variables (LVs) of the models by maximizing the covariance between $X$ and $Y$, avoiding the overfitting. The basis of the highest value of the determination coefficient (1-VR) and the lowest root mean square error of cross-validation (RMSECV) were the tools to study the predictive feasibility of the model. Additionally, to guarantee the reliability of the models in the classification of the different classes the Sensitivity (SE) and Specificity (SP) were calculated [17]. Thus, SE denotes the percentage of samples belonging to an established class that the studied model has recognized as belonging to that class:

$$
\mathrm{SE}=\mathrm{TP} /(\mathrm{TP}+\mathrm{TN})
$$

Whilst SP denotes the percentage of the number of samples that do not belong to the selected class and that the model has correctly rejected:

$$
\mathrm{SP}=\mathrm{TN} /(\mathrm{TN}+\mathrm{FP})
$$

being $\mathrm{TP}=$ true positives, $\mathrm{FN}=$ false negatives, $\mathrm{TN}=$ true negatives and $\mathrm{FP}=$ false positives

Calibration results from all pre-treatments and spectra ranges assessed are compiled in Table S1 (supplementary material), whilst results of the best fitting models (calibration and external validation) are summarized in Table 2.

Table 2. PLS-DA results of the best fitting equation for pre-sliced MAP Iberian chorizo classification within the official

\begin{tabular}{|c|c|c|c|c|c|c|c|c|c|c|c|}
\hline \multirow{2}{*}{$\begin{array}{l}\text { Commercial } \\
\text { Category }\end{array}$} & \multirow{2}{*}{ Pre-Treatment } & \multirow{2}{*}{$\begin{array}{c}\text { Range } \\
\text { (nm) }\end{array}$} & \multirow{2}{*}{ LVs } & \multicolumn{5}{|c|}{ Cross-Validation } & \multicolumn{3}{|c|}{ External Validation } \\
\hline & & & & $\mathrm{n}$ & 1-VR & RMSECV & SE & SP & $\mathrm{n}$ & SE & SP \\
\hline Black & SNV-DE & $1000-2300$ & 12 & 69 & 0.815 & 0.198 & 100.00 & 100.00 & 31 & 81.82 & 90.00 \\
\hline Red & $\begin{array}{l}\text { SG 1,4,4,1 } \\
\text { SNV-DE }\end{array}$ & $1000-2300$ & 10 & 70 & 0.838 & 0.181 & 96.00 & 97.87 & 31 & 60.00 & 66.67 \\
\hline White & $\begin{array}{l}\text { SG 1,4,4,1 } \\
\text { SNV-DE }\end{array}$ & $1000-2300$ & 10 & 70 & 0.790 & 0.245 & 100.00 & 95.65 & 31 & 70.00 & 71.43 \\
\hline
\end{tabular}
commercial categories of the raw material (Black, Red and White).

Black, Red and White = commercial categories of raw used for manufacturing Iberian chorizo; SNV = Standard normal variate; $\mathrm{DE}=$ de-trending; $\mathrm{SG}=$ Savitzky-Golay derivates; $\mathrm{LVs}=$ latent variables; $\mathrm{n}=$ number of samples; $1-\mathrm{VR}=$ coefficient of determination in cross-validation; RMSECV = root mean square error of cross validation; $\mathrm{SE}=$ sensitivity $(\%)$; SP = specificity (\%).

\subsubsection{Soft Independent Modelling of Class Analogies (SIMCA)}

SIMCA was evaluated in the current study as a class-modelling technique [18]. Thus, samples of unknown origin were used to obtain a classification rule able to discriminate samples of unknown origin into the different classes established, based on the values of the different characteristics of the samples themselves. Thus, SIMCA builds class models based on independent PCA models performed only on samples belonging to each class under study (Black, Red or White). The dimension of the individual PCA model is given by the number of principal components (PCs), determined by a cross-validation procedure. Samples do not have to be classified in only one of the above classes. The classification of new samples with unknown origin was calculated using the scores and the loadings of the created PCA model, taking into consideration the distance of the sample to the centre of the model (leverage), which provides information about the placement of the projected sample on the PCs, and the distance of the sample to the model defined by the PCs (S-distances).

Classification ability of the models were expressed on terms of SE and SP [17]. Calibration results from all pre-treatments and spectra ranges evaluated are compiled in Table S2 (supplementary material), whilst results of the best fitting models (calibration and external validation) are summarized in Table 3. 
Table 3. SIMCA results of the best fitting equation for pre-sliced MAP Iberian chorizo classification within the official commercial categories of the raw material (Black, Red and White).

\begin{tabular}{|c|c|c|c|c|c|c|c|c|c|}
\hline \multirow{2}{*}{ Commercial Category } & \multirow{2}{*}{ Pre-Treatment } & \multirow{2}{*}{ Range } & \multirow{2}{*}{ PCs } & \multicolumn{3}{|c|}{ Calibration } & \multicolumn{3}{|c|}{ External Validation } \\
\hline & & & & $\mathbf{n}$ & SE & SP & $\mathbf{n}$ & SE & SP \\
\hline Black & Absorbance & $1000-2300$ & 1 & 21 & 100.00 & 21.57 & 31 & 90.91 & 45.00 \\
\hline Red & SG $1,4,4,1$ & $1000-1800$ & 9 & 25 & 100.00 & 46.81 & 31 & 90.00 & 47.62 \\
\hline White & SNV-DE & $1000-1800$ & 1 & 26 & 100.00 & 63.04 & 31 & 90.00 & 47.62 \\
\hline
\end{tabular}

Black, Red and White = commercial categories of raw used for manufacturing Iberian chorizo; SG = Savitzky-Golay derivates; SNV = Standard normal variate; $\mathrm{DE}=$ de-trending; $\mathrm{PCs}=$ number of principal components; $\mathrm{n}=$ number of samples; $\mathrm{SE}=$ sensitivity $(\%) ; \mathrm{SP}=$ specificity $(\%)$.

\subsubsection{Linear Discriminant Analysis (LDA)}

LDA analysis is based on the description of data by means of probability density distributions, under the hypotheses that they are multivariate normal and with the same dispersion and correlation between variables within all the classes established [19]. The aim of LDA is to find a dimension reducing transformation that minimizes the dispersion within each class and maximizes the dispersion between them in a reduced dimensional space. The fact of requiring more rows than columns in the working matrix where all the data is included, is what limits this model, as it is in our case. In order to decrease the dimension of the spectral variables, the variables were previously reduced by PCA [20]. The class distance was calculated by the Mahalanobis method and the number of PCs was the optimal suggested by the PCA model [21]. The capacity assessment of the LDA model was carried out in SE and SP [17]. Calibration results from all pre-treatments and spectra ranges evaluated are compiled in Table S3 (supplementary material), whilst results of the best fitting models (calibration and external validation) are summarized in Table 4.

Table 4. LDA results of the best fitting equation for pre-sliced MAP Iberian chorizo classification within the official commercial categories of the raw material (Black, Red and White).

\begin{tabular}{|c|c|c|c|c|c|c|c|c|}
\hline \multirow{2}{*}{ Commercial Category } & \multirow{2}{*}{ Pre-Treatment } & \multirow{2}{*}{ Range } & \multicolumn{3}{|c|}{ Calibration } & \multicolumn{3}{|c|}{ External Validation } \\
\hline & & & $\mathbf{n}$ & SE & SP & $\mathbf{n}$ & SE & SP \\
\hline Black & SG $1,4,4,1$ & $1000-2300$ & 72 & 90.48 & 86.27 & 31 & 81.82 & 60.00 \\
\hline Red & SG $1,4,4,1$ SNV-DE & $1000-1800$ & 72 & 84.00 & 97.87 & 31 & 90.00 & 80.95 \\
\hline White & Absorbance & $1000-1800$ & 72 & 88.46 & 93.48 & 31 & 80.00 & 95.24 \\
\hline
\end{tabular}

Black, Red and White = commercial categories of raw material used for manufacturing Iberian chorizo; SG = Savitzky-Golay derivates; $\mathrm{SNV}=$ Standard normal variate; $\mathrm{DE}=$ de-trending; $\mathrm{n}=$ number of samples; $\mathrm{SE}=$ sensitivity $(\%) ; \mathrm{SP}=$ specificity $(\%)$.

\section{Results}

\subsection{Spectral Information}

The raw spectra data from calibration and validation sample sets of unopened presliced MAP packages of Iberian chorizo manufactured from raw material belonging to three commercial categories according to the current IQS [6] are shown in Figure 2.

The NIR spectra data revealed similar shapes regardless of the official commercial category of raw material, showing the same peaks and valleys along the entire scanned region (1000-2500 $\mathrm{nm}$ ) in both calibration (Figure 2A) and validation (Figure 2B) sample sets. Nevertheless, there were reflectance intensity differences due to commercial categories of raw material. Lower reflectance was observed by spectra from Iberian Chorizo from Black and Red categories, which overlapped along 1000-2500 nm compared to chorizo spectra from White category, which yielded higher reflectance intensity.

On the other hand, from the value $1900 \mathrm{~nm}$ onwards it can be observed the signal reached by the detector was very low and in the spectra range between 2300 and 2500 high spectral noise was observed. 

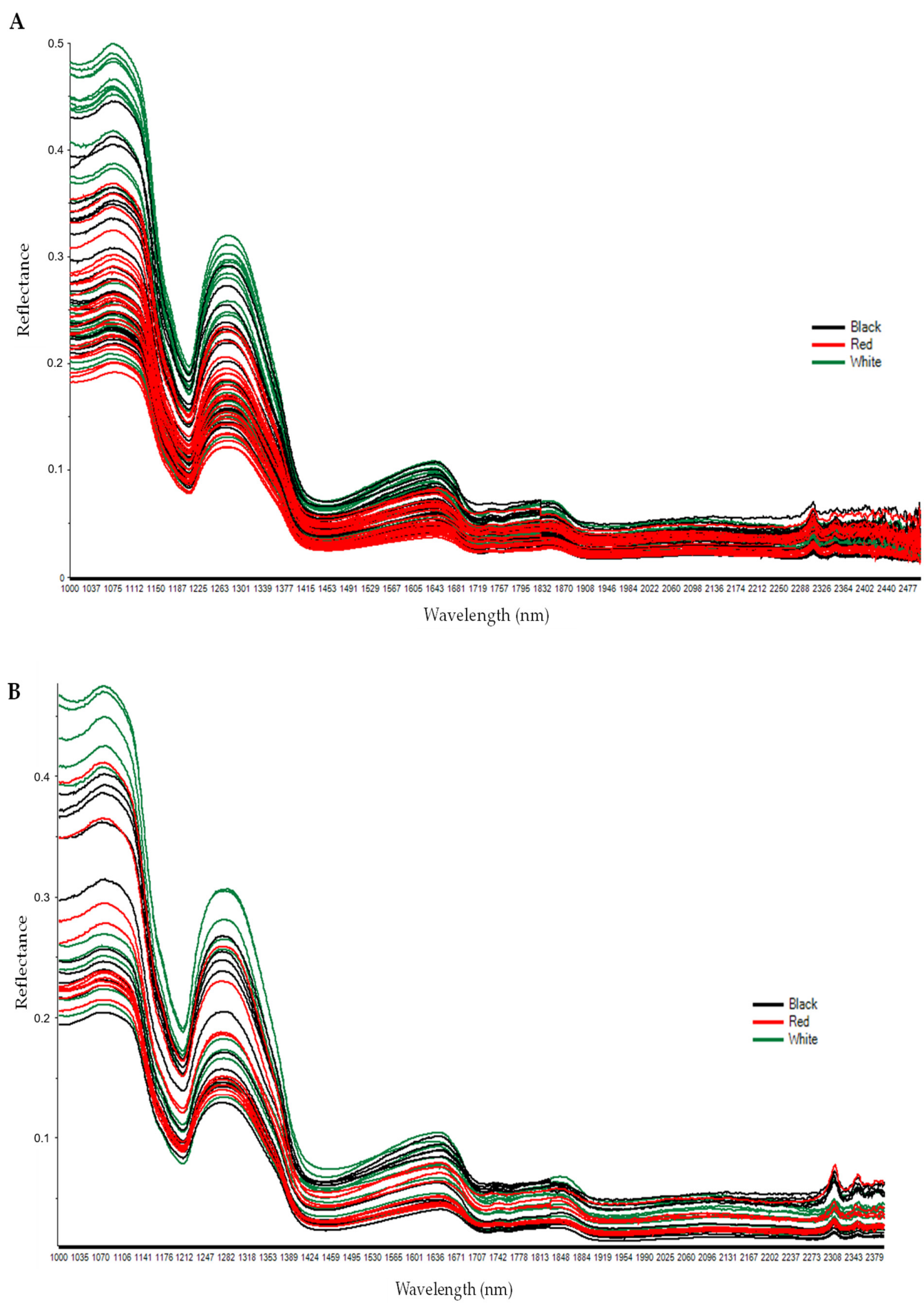

Figure 2. Raw spectra (reflectance) from calibration (A) and validation (B) sample set obtained from unopened pre-sliced MAP packaged Iberian Chorizo manufactured from raw material belonging to three official commercial categories (Black, Red and White).

Additionally, the regression coefficients of wavelengths of Iberian Chorizo from PLS-DA after SNV-DE (1000-2300 nm) for Black (Figure S2A) and SG 1,4,4,1 SNV-DE (1000-2300 nm) for Red and White (Figure S2B,C, respectively) were graphically presented in the supplementary material. It is important to note that for the black label, the wavelengths around $1100 \mathrm{~nm}$ and between $1200 \mathrm{~nm}$ and $1600 \mathrm{~nm}$ were the ones that stood out for their high weight (regression coefficients) (Figure S2A). Similarly, the wavelengths mainly comprised between $1000 \mathrm{~nm}$ and $1400 \mathrm{~nm}$ for Red (Figure S2B) and $1000 \mathrm{~nm}$ and $1500 \mathrm{~nm}$ for White (Figure S2C) category were the wavelengths that had the greatest weight. 


\subsection{Near Infrared Spectroscopy Qualitative Predictive Models}

3.2.1. Partial Least Squares-Discriminant Analysis Models for the Classification of Iberian Chorizo According to Commercial Categories of Raw Material

The combination of the SNV and DE (SNV-DE) pre-treatments for the Black category gave the best prediction result in PLS-DA in the spectra range comprised between 1000 and $2300 \mathrm{~nm}$ (Table 2). For both Red and White categories, the best fitting prediction models were derived from the combination of first derivative (SG 1,4,4,1) and SNV-DE in the 1000 and $2300 \mathrm{~nm}$ (Table 2). No substantial differences were observed between the 1-VR and RMSECV statistics among the best models for the three categories considered. Thus, 1-VR ranged from 0.790 for White model to 0.838 of Red one, whereas the RMSECV ranged from 0.181 to 0.245 for Red and White models, respectively. The SE and SP calibration values obtained for all the abovementioned calibration models were above $95 \%$.

When best PLS-DA fitting prediction models were validated (Table 2), the best SE and SP results were found for the SNV-DE 1000-2300 nm model, i.e., the best fitting predictive model for the Black category, with an $81.82 \%$ and $90.00 \%$, respectively. In any case, satisfactory classification results were also obtained for the rest of commercial categories when models were externally validated.

The PCA plots after the pre-treatments and in the spectra range from which the best fitting models were obtained are presented in Figure S3 of the supplementary material. It can be noted how the samples represented in principal components (PC) 1 and 2 tend to aggregate according to the commercial category of the raw material used, and therefore suggesting that discrimination among classes may be possible using the pre-treatments and spectra ranges above-mentioned. More in detail, samples from Black tended to have positive scores in both PC1 and PC2, Red samples were located to the left of PC1, whilst White samples had positive scores in PC1 and negative scores in PC2 (Figure S3).

\subsubsection{Soft Independent Modelling of Class Analogies Models for the Classification of} Iberian Chorizo According to Commercial Categories of Raw Material

The model where the best results were obtained for the black label was the raw spectrum in the range of 1000-2300 nm, while for the red and white category the SG 1,4,4,1 and SNV-DE (1000-1800 nm) pre-treatments were necessary to obtain the best SE and SP (Table 3). All these calibration models showed perfect SE (100\%). On the contrary, low SP values were found, especially for Black category (21.57\%). When external validation was applied, the results were less accurate in terms of SE, whilst SP values showed similar behavior to calibration sample set, even improving for the Black model.

In Figures S2-S5 (supplementary material) the SIMCA plots of both the sample-tomodel distance $(\mathrm{Si})$ and the sample leverage $(\mathrm{Hi})$ for a particular model are shown. The plots include the class membership limits for both statistics: (A) projection of calibration and (B) external validation samples set to the PCA model results from the pre-treatment and spectra range from which the best classification fitting models were obtained for Black, Red and White categories, respectively.

3.2.3. Linear Discriminant Analysis Models for the Classification of Iberian Chorizo According to Commercial Categories of Raw Material

The best SE and SP values in calibration models by LDA were attained with the use of SG 1,4,4,1, SG 1,4,4,1 SNV-DE and raw spectra (Reflectance) for Black, Red and White, respectively (Table 4). Normally, excellent results were obtained, with both SE and SP values above $84 \%$. Once external validation was applied, the SE and SP results were preserved, except in the case of the Black label, which experienced a decrease in the SP value to $60 \%$ (Table 4 ).

\section{Discussion}

The development of robust and reproducible predictive models to discriminate between different commercial categories of the raw material of pre-sliced MAP Iberian chorizo, first requires obtaining representative spectra for each study sample. Thus, between 1000 
and $2000 \mathrm{~nm}$, the noise was not noticeable (Figure 2), showing the spectra an area with high signal/noise ratio, and therefore the region with the most amount of useful data. Above $2300 \mathrm{~nm}$ spectra displayed little useful information, so these wavelengths were discarded for the models developed in this study. More specifically, the main absorption dominated bands were observed around 1090 and $1270 \mathrm{~nm}$, which would be associated with behavior to the C-H bonds, which is related to fatty acids and alpha and gamma tocopherols [22,23]. Therefore, the overlapping of spectra from Black and Red categories would support the similarity in the fatty acid profile (38.1 and $38.6 \mathrm{~g}$ per $100 \mathrm{~g}$ of fatty acid methyl esters (\% FAMEs) of saturated fatty acids, 54.8 and 54.5\% FAMEs of monounsaturated fatty acids and 7.2 and 6.8\% FAMES of polyunsaturated fatty acids for Black and Red categories, respectively), and tocopherols content (14.4 and $13.9 \mu \mathrm{g} / \mathrm{g}$ of alpha tocopherol and 1.7 and $1.6 \mu \mathrm{g} / \mathrm{g}$ of gamma tocopherol for Black and Red categories, respectively) between Iberian chorizo manufactured from meat and fat belonging to these two categories, as has been previously reported [8] and as has been also demonstrated in other Iberian dry-cured products $[24,25]$. This could be mainly explained by the same feeding regime of animals reared under the requirements of both Black and Red categories. Fernández-Cabanás et al. [26] also described bands located around $1210 \mathrm{~nm}$ corresponding to fatty acids when studying NIRS technology as rapid determination of the fatty acid profile in Spanish Iberian salchichón and chorizo dry-cured sausages. Later, Pérez-Marín et al. [27] also reported graphically that regions characteristic of $\mathrm{CH} 2$ absorption bands allowed some separations between samples of Iberian pig carcasses from animals with different feeding regime (acorns vs. compound feeds). Therefore, the ability to classify among the different categories may be ascribed to spectral differences, and more specifically, to these areas where the largest differences in absorbance intensity are found, i.e., the areas related to fatty acids (Figure 2), since the variables corresponding to these wavelengths proved to have an important weight in the development of the PLS-DA models (Figure S2). Spectra differences on account on animal feeding regime have been previously used for classification purposes. Thus, Pérez-Marín et al. [27] discriminated between carcasses of acorn-fed versus feed-fed Iberian pigs, whereas Horcada et al. [10] were able to classify Iberian pigs, carcass, meat and subcutaneous backfat according to animal feeding regime.

The models developed by means of PLS-DA showed acceptable SE and SP values after external validation. Therefore, these results suggest that the combination of NIRS technology with PLS-DA would provide models to be used for Iberian dry-cured chorizo under MAP classification according to the different quality labels of IQS. The same methodology has previously been used to classify fresh meat samples (psoas major muscle) into the same quality categories [10] and in pre-sliced MAP dry-cured loin [11]. Additionally, the PLS-DA chemometric algorithm in combination with spectroscopy techniques was also used for the discrimination between fresh versus frozen Iberian dry-cured loin [28]. In all studies, similar classificatory results to those obtained in the present research were found, concluding the high classificatory capacity of PLS-DA and enhancing its potential in official quality categories assignment support control. So, results of this work could be a preliminary breakthrough for use in cured, sliced and packaged sausage-type products. Similar SE but lower SP was found in the most reliable models developed by SIMCA with respect to PLS-DA. The high ability to detect samples not belonging to each of the commercial categories is very useful for the meat industrial sector, in terms of authenticity control of the most commercially relevant products (Black and Red) [5], as they are usually associated with a higher probability of fraud. Therefore, SIMCA does not provide desirable SP results to guarantee a correct application in cured products such as chorizo which attain the highest prices in the market and might be the most exposed to fraudulent practices. A similar pattern was observed in previous studies with dry-cured loin, sliced and packaged [11]. This chemometric approach has been tested in other matrices obtaining more satisfactory results. Thus, Pieszczek et al. [29] identified different ground meat species (beef, pork and lamb), meanwhile, Agudo et al. [30] discriminated between perirenal fat in lambs according to their feeding during fattening. Both studies obtained higher SP 
values, especially the former, probably explained by the greater differences in terms of composition than those found among the chorizos of the different categories in the present study. Finally, the classification capacity obtained by LDA reported good results in both parameters; SE and SP and between the different quality categories (IQS) in both calibration and validation sets, as reported in previous studies with cured loin [11]. In this line, LDA results of this study were similar to those reported for lamb perirenal fat discrimination according to animal feeding regime by $[30,31]$ when evaluating LDA to classify Iberian pig adipose tissue according to the animal feeding regime (acorns vs. commercial fodder). On the other hand, as previously mentioned, LDA models yielded higher SP values than those obtained by SIMCA in calibration and external validation sample sets, and higher than those obtained by PLS-DA in external validation for Red and White categories. So, these results may suggest that the more sophisticated chemometric classification methods; PLS-DA and specifically SIMCA, would not provide better classification results -after external validation-compared to the simplest approach (LDA), as recently concluded [30].

\section{Conclusions}

This research shows the feasibility of using NIRS technology in the Iberian meat sector for rapid of pre-sliced and packaged products quality control. NIR spectral pre-processing and chemometric approaches can be an alternative tool for the traceability and authenticity control of the individual pre-sliced MAP Iberian chorizo according to different official commercial categories of raw material compiled by the current Spanish Iberian Quality Standard used for its manufacture (Black, Red and White).

As the models were developed with direct contact measurements without opening the package, their reproducibility could be limited by the characteristics and type of plastic, as well as the composition of the gases inside the package.

Therefore, these results open a line of study aimed at evaluating the effectiveness of NIRS technology as an alternative tool for the assessment of other meat products packaged in other types of packaging, such as vacuum or active packaging.

Supplementary Materials: The following are available online at https:/ /www.mdpi.com/article/10 $.3390 /$ app112311379/s1, Figure S1. Spectral sampling (reflectance) of a sample of Iberian chorizo under modified atmosphere packaging with a LabSpec 2500 (ASD Inc., Madrid, Spain) NIRS spectrometer equipped with an ASD fibre-optic contact Probe ${ }^{\circledR}$ (21-mm window diameter). Figure S2: Graphical representation of the regression coefficients of the spectral data of Iberian Chorizo from PLS-DA analysis after SNV-DE (1000-2300 nm) for Black (A) and SG 1,4,4,1 SNV-DE (1000-2300 nm) for Red and White (B and C, respectively). Significant variables are highlighted in black. Figure S3: 2-D scatter PCA analysis plot of calibration sample set $(n=72)$ after SNV-DE (reflectance) at 1000-2300 nm (A), and after SG 1,4,4,1 SNV-DE (reflectance) at 1000-2300 nm (B). Samples were grouped by official commercial categories (Black, Red and White) of raw material used for manufacturing Iberian chorizo. Graphical representation of PC1 (51\%, 30\%, respectively) vs. PC2 (23\%, 19\%, respectively). Figure S4: SIMCA plot from spectra data showing both the sample-to-model distance (Si) and the sample leverage (Hi), including the class membership limits for projection of samples to Black PCA (reflectance) 1000-2300 nm model in calibration (A) and external validation (B) sample sets. Figure S5: SIMCA plot from spectra data showing both the sample-to-model distance ( $\mathrm{Si}$ ) and the sample leverage (Hi), including the class membership limits for projection of samples to Red PCA SG 1,4,4,1 (reflectance) 1000-1800 nm model in calibration (A) and external validation (B) sample sets. Figure S6: SIMCA plot from spectra data showing both the sample-to-model distance ( $\mathrm{Si}$ ) and the sample leverage (Hi), including the class membership limits for projection of samples to White PCA SNV-DE (reflectance) 1000-1800 nm model in calibration (A) and external validation (B) sample sets. Table S1: PLS-DA calibration results of models developed for pre-sliced MAP Iberian chorizo classification within the official commercial categories of the raw material (Black, Red and White) according to various spectral pre-treatments and spectra ranges. Table S2: SIMCA calibration results of models developed for presliced MAP Iberian chorizo classification within the official commercial categories of the raw material (Black, Red and White) according to various spectral pre-treatments and spectra ranges. Table S3: LDA calibration results of models developed for pre-sliced MAP Iberian chorizo classification within the 
official commercial categories of the raw material (Black, Red and White) according to various spectral pre-treatments and spectra ranges.

Author Contributions: Conceptualization, A.O. and D.T.; methodology, A.O., R.C. and L.L.; formal analysis, A.O. and L.L.; investigation, D.T.; writing-original draft preparation, A.O. and L.L.; writing-review and editing, D.T.; funding acquisition, D.T. All authors have read and agreed to the published version of the manuscript.

Funding: This piece of research was supported by FEDER funds (IB16182 and MEAT0) and Extremadura Regional Council (IB16182). Alberto Ortiz and Lucía León would like to thank the Extremadura Regional Council and the FEDER funds for the award of the pre-doctoral grant (PD16057) and the financing of the contract (PEJ 2018-004565-P), respectively.

Institutional Review Board Statement: Not applicable.

Informed Consent Statement: Not applicable.

Data Availability Statement: Data sharing not applicable.

Acknowledgments: The laboratory work of Meat Quality area of CICYTEX is acknowledged. Authors are grateful to Señorío de Montanera industry for manufacturing the samples of this research.

Conflicts of Interest: The authors declare no conflict of interest. The funders had no role in the design of the study; in the collection, analyses, or interpretation of data; in the writing of the manuscript, or in the decision to publish the results.

\section{References}

1. Pugliese, C.; Sirtori, F. Quality of meat and meat products produced from southern European pig breeds. Meat Sci. $2012,90$. [CrossRef]

2. Fuentes, V.; Ventanas, S.; Ventanas, J.; Estévez, M. The genetic background affects composition, oxidative stability and quality traits of Iberian dry-cured hams: Purebred Iberian versus reciprocal Iberian $\times$ Duroc crossbred pigs. Meat Sci. 2014, 96, 737-743. [CrossRef] [PubMed]

3. Ramírez, M.R.; Cava, R. Effect of Iberian x Duroc genotype on dry-cured loin quality. Meat Sci. 2007, 76, 333-341. [CrossRef] [PubMed]

4. Tejerina, D.; García-Torres, S.; Cabeza de Vaca, M.; Vázquez, F.M.; Cava, R. Effect of production system on physical-chemical, antioxidant and fatty acids composition of Longissimus dorsi and Serratus ventralis muscles from Iberian pig. Food Chem. 2012, 133, 293-299. [CrossRef]

5. Díaz-Caro, C.; García-Torres, S.; Elghannam, A.; Tejerina, D.; Mesias, F.J.; Ortiz, A. Is production system a relevant attribute in consumers' food preferences? The case of Iberian dry-cured ham in Spain. Meat Sci. 2019, 158, 107908. [CrossRef] [PubMed]

6. RD 4/2014 de 10 de Enero por el que se Aprueba la Norma de Calidad para la carne, el Jamón, la Paleta y la Caña de lomo Ibérico; Spanish Ministry of Agriculture, Fisheries and Food: Madrid, Spain, 2014. Available online: https://www.boe.es/diario_boe/txt.php?id= BOE-A-2014-318 (accessed on 7 October 2021).

7. García-Gudiño, J.; Blanco-Penedo, I.; Gispert, M.; Brun, A.; Perea, J.; Font-i-Furnols, M. Understanding consumers' perceptions towards Iberian pig production and animal welfare. Meat Sci. 2021, 172, 108317. [CrossRef]

8. García-Torres, S.; Contador, R.; Ortiz, A.; Tamírez, R.; López-Parra, M.M.; Tejerina, D. Physico-chemical and sensory characterization of sliced Iberian Chorizo from raw material of three commercial categories and stability during refrigerated storage packaged under vacuum and modified atmospheres. Food Chem. 2021, 354, 129490. [CrossRef]

9. García-Esteban, M.; Ansorena, D.; Astiasarán, I. Comparison of modified atmosphere packaging and vacuum packaging for long period storage of dry-cured ham: Effects on colour, texture and microbiological quality. Meat Sci. 2004, 67, 57-63. [CrossRef] [PubMed]

10. Horcada, A.; Valera, M.; Juárez, M.; Fernández-Cabanás, V.M. Authentication of Iberian pork official quality categories using a portable near infrared spectroscopy (NIRS) instrument. Food Chem. 2020, 318, 126471. [CrossRef]

11. Tejerina, D.; Contador, R.; Ortiz, A. Near infrared spectroscopy (NIRS) as tool for classification into official commercial categories and shelf-life storage times of pre-sliced modified atmosphere packaged Iberian dry-cured loin. Food Chem. 2021, $356,129733$. [CrossRef]

12. Barnes, R.; Dhanoa, M.; Lister, S. Standard normal variate transformation and de-trending of near infrared diffuse reflectance spectrea. Appl. Spectrosc. 1989, 43, 772-777. [CrossRef]

13. Savitzky, A.; Golay, M.J.E. Smoothing and Differentiation of Data by Simplified Least Squares Procedures. Anal. Chem. 1964, 36, 1627-1639. [CrossRef]

14. Faber A closer look at the bias-variance trade off in multivariate calibration. J. Chemom. 1999, 13, 185-192. [CrossRef] 
15. Pérez-Marín, D.C.; Garrido-Varo, A.; Guerrero, J.E. Optimization of Discriminant Partial Least Squares Regression Models for the Detection of Animal By-Product Meals in Compound Feedingstuffs by Near-Infrared Spectroscopy. Appl. Spectrosc. 2006, 60, 1432-1437. [CrossRef] [PubMed]

16. Geladi, P.; Davies, T. Book Reviews: A User-Friendly Guide to Multivariate Calibration and Classification, An Academic Addition to the NIR Bookshelf. NIR News. 2002, 13, 12-13. [CrossRef]

17. Oliveri, P.; Malegori, C.; Casale, M. Multivariate Classification Techniques. In Reference Module in Chemistry, Molecular Sciences and Chemical Engineering; Elsevier: Amsterdam, The Netherlands, 2018.

18. Wold, S.; Sjöström, M. SIMCA: A Method for Analyzing Chemical Data in Terms of Similarity and Analogy. In Chemometrics: Theory and Application; ACS Publications: Washington, DC, USA, 1977.

19. Fisher, R.A. The use of multiple measurements in taxonomic problems. Ann. Eugen. 1936, 7, 179-188. [CrossRef]

20. Liu, L.; Cozzolino, D.; Cynkar, W.U.; Gishen, M.; Colby, C.B. Geographic Classification of Spanish and Australian Tempranillo Red Wines by Visible and Near-Infrared Spectroscopy Combined with Multivariate Analysis. J. Agric. Food Chem. 2006, 54, 6754-6759. [CrossRef] [PubMed]

21. Naes, T.; Isaksson, T.; Fearn, T.; Davies, T. A User-Friendly Guide to Multivariate Calibration and Classification; NIR Publications: Chichester, UK, 2002.

22. Murray, J.M.; Delahunty, C.M.; Baxter, I.A. Descriptive sensory analysis: Past, present and future. Food Res. Int. 2001, 34, 461-471. [CrossRef]

23. Barbin, D.F.; de Felicio, A.L.S.M.; Sun, D.-W.; Nixdorf, S.L.; Hirooka, E.Y. Application of infrared spectral techniques on quality and compositional attributes of coffee: An overview. Food Res. Int. 2014, 61, 23-32. [CrossRef]

24. Contador, R.; Ortiz, A.; Ramírez, M.; del Rosario Ramírez, M.; García-Torres, S.; López-Parra, M.M.; Tejerina, D. Physico-chemical and sensory qualities of Iberian sliced dry-cured loins from various commercial categories and the effects of the type of packaging and refrigeration time. LWT 2021, 141, 110876. [CrossRef]

25. Ramírez, R.; Contador, R.; Ortiz, A.; García-Torres, S.; López-Parra, M.M.; Tejerina, D. Effect of Breed Purity and Rearing Systems on the Stability of Sliced Iberian Dry-Cured Ham Stored in Modified Atmosphere and Vacuum Packaging. Foods 2021, 10, 730. [CrossRef]

26. Fernández-Cabanás, V.M.; Polvillo, O.; Rodríguez-Acuña, R.; Botella, B.; Horcada, A. Rapid determination of the fatty acid profile in pork dry-cured sausages by NIR spectroscopy. Food Chem. 2011, 124, 373-378. [CrossRef]

27. Pérez-Marín, D.; Fearn, T.; Riccioli, C.; De Pedro, E.; Garrido, A. Probabilistic classification models for the in situ authentication of iberian pig carcasses using near infrared spectroscopy. Talanta 2021, 222, 121511. [CrossRef] [PubMed]

28. Cáceres-Nevado, J.M.; Garrido-Varo, A.; De Pedro-Sanz, E.; Tejerina-Barrado, D.; Pérez-Marín, D.C. Non-destructive Near Infrared Spectroscopy for the labelling of frozen Iberian pork loins. Meat Sci. 2021, 175, 108440. [CrossRef] [PubMed]

29. Pieszczek, L.; Czarnik-Matusewicz, H.; Daszykowski, M. Identification of ground meat species using near-infrared spectroscopy and class modeling techniques-Aspects of optimization and validation using a one-class classification model. Meat Sci. 2018, 139, 15-24. [CrossRef]

30. Agudo, B.; Delgado, J.V.; López, M.M.; Rodríguez, P.L. Comparación de herramientas quimiométricas de clasificación para la identificación de grasa perirrenal en corderos. Arch. Zootec. 2020, 69, 6-12. [CrossRef]

31. Piotrowski, C.; Garcia, R.; Garrido-Varo, A.; Pérez-Marín, D.; Riccioli, C.; Fearn, T. Short Communication: The potential of portable near infrared spectroscopy for assuring quality and authenticity in the food chain, using Iberian hams as an example. Animal 2019, 13, 3018-3021. [CrossRef] 